\title{
MODELOS PARA A FORMAÇÃO DE PROFESSORES NAS PÁGINAS DO TEACHERS COLLEGE RECORD (1900-1921)
}

DOI: http://dx.doi.org/10.1590/2236-3459/56586

\author{
Vera Teresa Valdemarin \\ Universidade Estadual Paulista, Brasil.
}

$\cos 80$

\begin{abstract}
Resumo
Este texto objetiva caracterizar os modelos de formação de professores postos em circulação pelo Teachers College da Universidade Colúmbia, sediado na cidade de Nova York, nas primeiras décadas do século 20. A fonte documental utilizada é o periódico Teachers College Record, que servia aos propósitos de divulgar o trabalho desenvolvido na instituição e contribuir para a construção da sua reputação acadêmica. Questões relativas à como ensinar constituíram o eixo concepções para a formação de professores. de ensino.

\section{MODELS FOR TEACHER TRAINING IN THE PAGES OF TEACHERS COLLEGE RECORD (1900-1921)} da análise, em torno do qual foi possível detectar o entrelaçamento de objetivos pedagógicos, metodológicos e políticos que embasavam propostas de mudanças de procedimentos e de

Palavras-chave: educação norte-americana, Teachers College, formação de professores, métodos

\section{Abstract}

This article aims to characterize the teacher training models put into circulation by the Teachers College of Columbia University, headquartered in New York, in the early decades of the 20th century. The documentary source used in the article is the periodical Teachers College Record, which used to serve the purposes of disseminating the work developed in the institution and contributing to the construction of its academic reputation. Issues related to "how to teach" formed the axis of this analysis, on which it was possible to detect the intermingling of the teaching, methodological and political objectives that supported proposals for changes in procedures and in conceptions towards teacher training.

Key-words: American education, Teachers College, teacher training, teaching methods. 


\section{MODELOS PARA LA FORMACIÓN DE PROFESORES EN LAS \\ PÁGINAS DEL TEACHERS COLLEGE RECORD (1900-1921)}

\section{Resumen}

El presente artículo objetiva caracterizar los modelos de formación de profesores puestos en circulación por el Teachers College de la Universidad Columbia, con sede en la ciudad de Nueva York, en las primeras décadas del siglo 20. La fuente documental utilizada es el periódico Teachers College Record, que servía a los propósitos de divulgar el trabajo desarrollado en la institución y aportar para la construcción de su reputación académica. Cuestiones relativas a cómo enseñar constituyeron el eje del análisis, en torno al cual fue posible detectar el entrelazamiento de objetivos pedagógicos, metodológicos y políticos que basaban propuestas de cambios de procedimientos y de concepciones para la formación de profesores.

Palabras-clave: educación norteamericana, Teachers College, formación de profesores, métodos de enseñanza.

\section{DES MODĖLES POUR LA FORMATION DES ENSEIGNANTS DANS LES PAGES DE TEACHERS COLLEGE RECORD (1900-1921)}

\section{Résumé}

Le présent article vise à caractériser les modèles de formation des enseignants mis en circulation par le Collège des Enseignants (Teachers College) de l'Université Columbia, dont le siège est à New York, dans les premières décennies du 20e siècle. La source documentaire utilisée est le périodique Teachers College Record, qui a servi les objectifs de diffuser les travaux développés dans l'institution et de contribuer à la construction de sa réputation académique. Les questions concernant l'enseignement forment l'axe de l'analyse, autour duquel il était possible de détecter l'entrelacement des objectifs pédagogiques, méthodologiques et politiques qui soutenaient les propositions de changements dans les procédures et les conceptions par rapport la formation des enseignants.

Mots-clé: éducation américaine, Teachers College, formation des enseignants, méthodes d'enseignement. 
$\mathrm{A}^{\mathrm{s}}$ s iniciativas para a formação sistemática de professores nos Estados Unidos da América remontam às décadas de 1830 e 1840 e prosseguiram com a criação de escolas normais em quase todos os Estados. Lentamente, a princípio, e por volta da década de 1880, a formação de professores começou a ser integrada à educação superior, com a criação de departamentos, escolas ou faculdades de Educação nas universidades (Fraser, 2007; Ogren, 2005). A coexistência de diferentes graus e arranjos institucionais dedicados ao mesmo objetivo, no entanto, não foi isenta de tensões, uma vez que estavam em jogo questões relativas à formação profissional, à pesquisa em educação e ao status dos estudos educacionais no sistema universitário.

No equacionamento institucional dessas questões, as escolas normais praticamente desapareceram do sistema educacional entre os anos de 1910 e 1920 e as universidades assumiram a formação de professores primários, secundários e dos profissionais para a ocupação de cargos de liderança na hierarquia escolar. Nesse processo, tornaram-se centros de renovação do pensamento pedagógico, interferindo no cenário educacional não apenas com os cursos regulares, mas por meio de pesquisas e publicações periódicas, do incentivo à criação de associações profissionais, de debates sobre os rumos da sociedade e do valor social da educação.

Período de grandes transformações - desenvolvimento urbano, econômico e social e eclosão da Primeira Guerra Mundial -, as décadas iniciais do século 20 impulsionaram redefinições sobre as necessidades educativas que perpassaram valores, convicções e práticas pedagógicas e cujos resultados alçaram os Estados Unidos à posição de influência inconteste no pensamento educacional, sendo difundidas para inúmeros países como símbolo, não apenas educacional, do desenvolvimento norte-americano.

Nesse contexto de transformações, o presente artigo objetiva caracterizar os modelos de formação de professores postos em circulação pelo Teachers College da Universidade Colúmbia, sediado na cidade de Nova York, resultantes da combinação de vários fatores. O primeiro deles é a elevação dos requisitos exigidos para o ingresso, marcando, por meio da certificação, o nível superior de instrução. Internamente as principais marcas provinham da articulação de diferentes instituições de ensino - do jardim de infância ao ensino médio - que eram, simultaneamente, evidência das realizações e espaços para experimentação de novas propostas que, por sua vez, demonstravam a relevância social da pesquisa. Os sucessivos acordos realizados com a universidade Columbia e as exigências sempre crescentes, transformaram-se em justificativas para a contratação de um corpo docente comprometido com a ideia de inovação que, ao longo do tempo, consolidou áreas de conhecimento, tanto por meio de filiações, quanto de controvérsias, e desenhou uma concepção do campo pedagógico composta de elementos teóricos e práticos.

A fonte documental eleita para a análise é o periódico Teachers College Record, criado em 1900, que servia aos propósitos de divulgar o trabalho desenvolvido na instituição e contribuía para a construção da sua reputação acadêmica, criando uma rede de sociabilidade (Sirinelli,1998) que fazia ressoar o trabalho de seus intelectuais e firmava grupos de afinidades e de concorrência em torno de concepções educacionais.

A divulgação do trabalho realizado constituiu via eficiente na criação dessa referência. O diálogo com as questões da cidade, enfrentadas com atividades de pesquisa e extensão, palestras abertas à comunidade, cursos de verão, intercâmbio de 
estudantes, estímulo à criação de associações e, mais especificamente, a publicação do periódico Teacher College Record, serviram de veículo para articular as questões doutrinárias com as práticas pedagógicas conferindo, assim, novos sentidos para a formação de professores alavancados por uma complexa organização institucional, pelo elevado desempenho profissional e pela atenção às demandas da sociedade. $\mathrm{Na}$ dinâmica desse processo multiplicam-se os protagonistas e suas proposições adquirem maior ressonância respaldadas cientificamente pelo lastro prático e experimental.

O corpus documental para a análise das mudanças nas concepções de formação de professores são artigos publicados no periódico entre 1900 e $1921^{1}$ que tratavam, especificamente, do tema ou que, abordando questões relacionadas ao ensino, indicavam implicações ou descreviam novas necessidades para o trabalho docente. Na leitura realizada, como ensinar foi configurado como o eixo em torno do qual pode ser percebido o entrelaçamento de objetivos pedagógicos, metodológicos e políticos que embasavam os novos rumos educacionais e o futuro entrevisto para a sociedade.

\section{A constituição do Teachers College como instituição exemplar na formação de professores}

Desde a primeira edição, em 1900, o periódico Teachers College Record apresenta, na versão de vários autores, a narrativa da incorporação do Teachers College da cidade de Nova York à Universidade Colúmbia como a realização de um anseio para o qual confluíram diferentes iniciativas. Por um lado o surgimento, em 1884, de uma instituição para formar professores que, de início filantrópica, desenvolveu-se sob a direção de Nicholas Murray Butler ${ }^{2}$ (1887-1891) reunindo escola de formação de professores, escola para crianças e jovens, do jardim de infância ao curso médio, e classes especiais, e, por outro lado, o interesse da Universidade em criar um departamento no qual a educação pudesse ser tratada como ciência, como campo de reflexões e estudos que resultassem em contribuições permanentes para a literatura educacional (Hervey, 1900).

Por meio de acordo celebrado em 1898 o Teachers College existente na cidade foi incorporado à estrutura da Universidade Columbia, que era organizada com três tipos de instituições: 1) os colégios, dedicados ao ensino de graduação - Columbia College e Barnard College - subsequentes ao ensino médio, com duração de quatro anos, destinados à obtenção do título de bacharel em Artes, cujo último ano deveria ser cursado em uma das faculdades; 2) as faculdades - de Filosofia, de Ciência Política e de Ciência Pura - cujo pré-requisito para o ingresso era o bacharelado, voltadas para a pesquisa e onde se poderia obter os títulos de mestre em Artes e Doutor em Filosofia e 3) as escolas

\footnotetext{
${ }^{1}$ O periódico Teachers College começou a ser publicado em 1900 e existe até hoje, podendo ser consultado no endereço <https://www.tcrecord.org>. Entre 1900 e 1921 eram publicados cinco volumes ao ano.

2 Nicholas Ray Butler doutorou-se em Filosofia sob a orientação de Frederick Barnard, que ocupava a presidência do Columbia College, e realizou estudos na Alemanha e na França. Ao assumir a presidência do conselho que dirigia a Industrial Education Association transformou os objetivos filantrópicos da instituição em objetivos educacionais e organizou o currículo do curso de formação de professores ampliando seus componentes acadêmicos (Towsend, 1954) 
profissionais - de Direito, de Medicina, de Ciências Aplicadas e o Teachers College dedicado ao estudo da educação e à formação de professores e de lideranças educacionais ${ }^{3}$.

Um complexo arranjo administrativo possibilitava que alguns professores atuassem como professores ou como conselheiros na Faculdade de Filosofia, na Faculdade de Ciências Aplicadas e no Teachers College. Havia, no entanto, hierarquia nessa estrutura, que se evidenciava, por exemplo, na prerrogativa de expedir a certificação dos diplomados: desde 1900 o Teachers College adquiriu autonomia para certificar os cursos de graduação, mas somente em 1915 o grau de mestre em educação deixou de ser expedido pela Faculdade de Filosofia. A alta qualificação do corpo docente certamente contribuiu para a conquista dessa autonomia, que estava também entrelaçada à manutenção de um padrão de excelência, próprio da Universidade, a ser assumido pelo Teachers College.

James Russel explicita, numa sequência de artigos, as características que distinguiriam o Teachers College. A competição então existente no campo educacional, oferta de melhores salários aos melhores profissionais, consistia, segundo ele, excelente oportunidade para a criação de cursos que oferecessem cultura geral, conhecimento profissional, conhecimento especializado e desenvolvimento de habilidades necessárias ao ensino. Estas qualificações, reconhecíveis na prática pedagógica dos profissionais, deveriam ser assumidas pelo Teachers College a fim de criar um código de marcas profissionais (Russel, 1900a), assentado nas seguintes disciplinas: Psicologia da Educação, História da Educação, Princípios da Educação e Teoria e Prática do Ensino. Amparado em bases científicas, esse conjunto de conhecimentos deveria contemplar os saberes relacionados à criança e à sociedade, aos padrões de cultura e aos ideais de vida e civilização, às teorizações sobre a mente humana e a aprendizagem e às bases confiáveis para a prática educacional (Russel, 1900a).

A área de teoria e prática do ensino, responsável pelo conhecimento profissional e especializado, deveria abordar a educação como ciência e como arte, isto é, aplicar as leis do desenvolvimento mental na observação, no planejamento e no ensino de lições dos diferentes conteúdos ensinados na escola ${ }^{4}$, o que exigia um período de formação sob condições reais de sala de aula.

\footnotetext{
${ }^{3}$ A concepção multidimensional de formação profissional do Teachers College consistia em cursos de 3 níveis. A graduação, com quatro anos de duração - dois anos introdutórios e dois anos dedicados à formação profissional -, que possibilitava atuar na escolar elementar e na educação infantil, e cursos de graduação para formar professores e supervisores nas áreas de Arte e Desenho, Artes Domésticas, Ciência Doméstica e Trabalhos Manuais; cursos de pós-graduação de um ano que, além de frequência a disciplinas exigiam a realização de pesquisa e investigação e eram destinados à elevação da qualificação de professores das escolas normais, diretores, supervisores e superintendentes de escolas, que já possuíssem graduação e comprovassem os requisitos acadêmicos ou experiência profissional. Eram oferecidos ainda cursos especiais para professores de escolas secundárias, portadores de diploma de bacharel, dedicados ao aprofundamento do conhecimento em áreas específicas e que poderiam ser combinados com outras atividades para obtenção do título de mestre (Russell, 1900b).

${ }^{4}$ Tendo por base a psicologia geral, a área de Teoria e Prática do Ensino buscava desenvolver métodos científicos para o ensino dos diferentes conteúdos escolares e oferecia os seguintes cursos: métodos para a educação infantil; métodos para a educação primária; crítica do ensino e princípios e métodos de ensino de Inglês, Francês, Alemão, Grego, Latim, História, Matemática, Biologia, Geografia e Geologia, Química, Física, Arte e Desenho, Economia Doméstica e Trabalhos Manuais. Era, portanto, elemento central na formação de professores primários e de professores secundários. 
Para tanto, faziam parte da estrutura do Teachers College duas escolas de observação e prática de ensino, entendidas como laboratório de estudo e pesquisa (Russel, 1900c). Trata-se da Horace Mann School e da Speyer School que, de modo complementar, explicitavam o código de marcas profissionais almejado pelo Teachers College. A Horace Mann era composta por três departamentos: Jardim da Infância, para crianças de 3 a 6 anos; Curso Elementar, composto por 8 séries, e, posteriormente, Curso Médio, composto por 4 séries, cobrava altas taxas de seus alunos e, nas palavras de seu superintendente, destinava-se a "ilustrar os princípios da boa educação e mostrar modelos de bom ensino para os estudantes do Teachers College" (Dutton, 1904, p. 1). Não era, portanto, uma escola para a prática, mas sim para a observação, inclusive de visitantes, que poderiam atestar a qualidade do trabalho ali desenvolvido. Entre os princípios norteadores da escola estavam a procedência social dos alunos, cujos valores culturais e morais eram comuns aos da instituição, os cuidados com o corpo e com a saúde, o cultivo do pensamento, da expressão e do ponto de vista ético. Segundo o autor, correlação é a palavra que melhor expressaria a unidade pretendida no ensino ali mantido.

A Speyer School ou Escola Experimental oferecia curso de Jardim da Infância, Curso Elementar e cursos especiais - costura, culinária e trabalhos manuais. Era gratuita e destinada às crianças da região que, de outro modo, não poderiam continuar seus estudos. Estatutariamente o cargo de diretor da Speyer School era ocupado pelo professor de Teoria e Prática de Ensino do Teachers College, uma vez que as atividades ali desenvolvidas constituíam parte regular e minuciosamente detalhada da formação de professores.

Frank McMurry ${ }^{5}$ ocupava essas posições e, em diferentes artigos, descrevia a operacionalização do trabalho realizado que, na verdade, consistia numa descrição do método para formar professores e do método a ser empregado no ensino. Para ele a obtenção de conhecimento em primeira mão sobre a atividade docente, embora de difícil execução, constituía tendência em diferentes ramos do conhecimento e, no caso da educação, só poderia ser realizada após o estudante ter cursado as disciplinas que lhe dariam fundamentação. A primeira tarefa a ser realizada pelos estudantes consistia no estudo sobre a Speyer School - exame de documentação, visitas à escola e aos arredores, conversas com seus profissionais -, observação minuciosa dos alunos nos períodos de aula e de recreação, exame do currículo de uma das classes para observar como se concretizava a relação entre os diferentes ramos do conhecimento, os materiais disponíveis para o ensino e as condições das salas de aulas. Durante a realização dessa etapa os futuros professores poderiam ser convidados a tomar conta da classe, coletar e distribuir materiais, corrigir trabalhos, estudar e propor soluções para algum problema específico.

\footnotetext{
${ }^{5}$ Frank McMurry desenvolveu estudos na Alemanha e era filiado ao Herbart Club, que tinha entre seus princípios a defesa da educação como modeladora do caráter. Além disso, argumentava que, para se tornar ciência, a educação deve proceder indutivamente, isto é, amparar-se em dados de pesquisa empírica (McMurry, 1904). 
A segunda etapa consistia na elaboração de um plano de lições, a ser preparado em caderno próprio e, nesse plano, deveriam ser apresentados, separadamente, a matéria ou fatos a serem ensinados, nas páginas à esquerda, e o método ou a maneira de apresentar esses fatos, nas páginas à direita, com a seguinte justificativa:

A primeira razão para a separação completa desses dois tipos de questões é que é necessário, na preparação de um bom plano, pensar a matéria independente do método e antes do método ser considerado. É muito comum que professores iniciantes determinem seu método de apresentar um tópico antes de terem certeza de que sabem os fatos que estão sendo ensinados. $\mathrm{E}$ quando a matéria e o método são reunidos, professores não percebem facilmente sua ignorância sobre os fatos. Seu método é seriamente afetado; uma razão para tantos métodos ruins é que os fatos não foram claramente concebidos. $^{6}$ (McMurry, 1903, p. 64)

Os planos, elaborados segundo essas normas, eram submetidos à crítica dos professores da escola (que também supervisionariam sua execução), sujeitos a revisões e testes e, finalmente, postos em prática pelos futuros professores.

Além dos cursos de formação outra via ampla e eficientemente manejada pelo Teachers College Record, para constituir-se como referência na formação de professores, era a apresentação dos programas desenvolvidos em suas escolas anexas, disseminando modelos de organização curricular. Desse modo dialogava com o público externo professores, lideranças educacionais e outros interessados - fornecendo conteúdo e inspiração para quem não obteve a formação profissional minuciosamente prescrita pela instituição.

Frank McMurry (1903) descreve o currículo do jardim da infância e das cinco séries da escola elementar desenvolvido na Speyer School, salientando que o programa de Exercícios Físicos pode ser utilizado em diferentes séries e escolas, inclusive na Horace Mann School, e abrange conteúdos rítmicos, ginástica formal, marcha, jogos com e sem música e atividades intra e extra classe. O currículo da série inicial era baseado no estudo e reprodução das ocupações e dos ambientes conhecidos pelas crianças, tais como a casa, a rua, os estabelecimentos da vizinhança. Nas séries seguintes era tematizada a vida primitiva e suas realizações e a quarta série centrava-se no estudo da história grega. Por meio desses temas deveriam ser trabalhados os conteúdos relativos às ciências naturais, história, geografia, aritmética, trabalhos manuais, linguagem e expressão.

Samuel Dutton e Henry Pearson (1904), respectivamente superintendente e diretor, afirmam que o currículo do curso elementar da Horace Mann School visava ao desenvolvimento das habilidades do homem cultivado, uma vez que os alunos são provenientes de lares confortáveis, nos quais os jornais, livros, obras de arte e viagens compõem uma parcela da tradição familiar. As matérias estudadas são Inglês, Matemática, Geografia, História, Estudo da Natureza, Trabalhos Manuais, Artes,

\footnotetext{
${ }^{6}$ The primary reason for this complete separation of two very different kinds of matter is that it is necessary, in preparing a good plan, to think subject matter through independently of method, and indeed, before method is considered. It is very common for teachers to begin determining their method of presenting a topic, before making sure that they know the facts which are to be taught. And when subject matter and method thus become mixed, teachers are not easily made conscious of their ignorance of facts. Their method, too, is then seriously affected; one reason for much bad method being that the facts to be taught have not been clearly conceived. 
Educação Física, Música e Francês, na sétima série. O professor de Trabalhos Manuais, Charles Richards (1904), explica como nas séries iniciais pretendia desenvolver unidade e continuidade entre a escola e a vida social por meio do estudo dos modos de subsistência, isto é, caça e pesca, pastoreio e agricultura e atividades industriais.

Do cotejamento entre os programas das duas escolas pode-se depreender que os elementos comuns são as orientações que presidem os programas de Educação Física e de Trabalhos Manuais, uma vez que a diferença é facilmente percebida, tanto em termos da organização formal do conhecimento, quanto em termos do aprofundamento e extensão no tratamento das matérias.

Nessa via, os números e volumes da revista são compostos tematicamente e dedicados à descrição detalhada de programas de ensino para os diferentes graus. Em alguns deles a organização se apresenta em torno das disciplinas, em outros pela reunião das disciplinas de uma mesma série ou ano escolar. No ano de 1900 (v. 1, n. 4) são apresentados os programas de Princípios da Educação, História da Educação, Administração Escolar e Sistemas Educacionais Nacionais, ministrados no curso de formação de professores. Os programas das disciplinas do ensino secundário desenvolvidos na escola Horace Mann, tais como Química, Matemática e Língua Inglesa, entre outros, são publicados com a apresentação dos objetivos, finalidades, temas a serem desenvolvidos em cada uma das séries, procedimentos didáticos e bibliografia destinada aos professores.

Tal como apresentada no periódico a excelência do trabalho desenvolvido na Teacher School comportava acréscimos, mudanças e complementações decorrentes das reflexões e pesquisas realizadas. Os programas da Horace Mann School foram publicados novamente nos anos de 1906 e 1907 e em 1913 (v. 14, n. 2 e 3) incluíram mudanças decorrentes de estudos e discussões. Entre as alterações programáticas mais relevantes está a tentativa para aproximar os conteúdos escolares de situações próprias da vida das crianças. Em Aritmética, Geografia e Música, por exemplo, indica-se que sejam incluídas questões relativas à cidade de Nova York, com o objetivo de estimular a participação e a formação de cidadãos envolvidos com os problemas da cidade. $O$ programa de História teve alguns temas condensados e foram agregados novos recursos, entre eles a fotografia, para abordar também possibilidades de registro do presente. $\mathrm{Na}$ primeira série do curso elementar o programa deveria ter início com questões relativas ao lar e prosseguir com lições baseadas em excursões e em atividades desenvolvidas no tanque de areia, centradas na vizinhança e nas ocupações sociais. Tais mudanças parecem indicar que, mantendo a formalidade na organização do conteúdo, alguns temas desenvolvidos no programa da escola experimental provaram sua pertinência.

A pesquisa como motor da mudança também é invocada como argumento das alterações no jardim da infância. Em 1904 foram publicados artigos que descreviam o programa e as instalações necessárias ao bom funcionamento desse nível educacional que começava a ser disseminado em alguns estados norte-americanos, notadamente com o objetivo de estabelecer um padrão para essas iniciativas. Em 1905 (v. 6, n. 4) foi reproduzido no periódico um curso sobre as teorias educacionais de Herbart e Froebel e a evolução das ideias pedagógicas. 
No ano de 1914, entretanto, um dos números do periódico (v. 15, n. 1) é dedicado às mudanças provocadas pelos estudos experimentais desenvolvidos no jardim da infância da escola Horace Mann, abrangendo aspectos teóricos e práticos. Assinados pela professora Patty Smith, o conjunto de textos rememora o trabalho de suas antecessoras, mas valoriza o espírito crítico dominante na instituição que incentiva a adoção de novas perspectivas e não a adesão cega às tradições. Para a autora, a liberdade de investigação imperou nas últimas décadas para a condução de experiências e, aliada a novas proposições, foi modificada a compreensão sobre a capacidade racional da criança na primeira infância. A síntese dessas orientações encontra sua fundamentação teórica nas proposições de John Dewey, apresentadas em conferência no Teachers College em 1913 (Hill e Dewey, 1914), na qual afirma que tão importante quanto os materiais utilizados são as atividades realizadas conjuntamente com outras pessoas que permitem à criança modular seu comportamento.

Pode-se dizer, portanto, que em sua primeira década de circulação o periódico divulgou o trabalho desenvolvido no Teachers College caracterizando-o como portador de excelência acadêmica compatível com os padrões da Universidade Colúmbia. O volume e o detalhamento dos programas das escolas anexas não deixam dúvidas sobre a intenção de vincular ensino e experimentação e, por meio deles, depreende-se que os elementos essenciais à formação de professores eram o que ensinar e como ensinar, isto é, conteúdo e método. O modo de elaboração desses programas - pesquisa empírica e teórica - modelava também o campo pedagógico.

\section{A renovação dos métodos de ensino e as implicações para a formação de professores nas páginas do Teachers College Record}

A partir de 1911 é possível detectar mudanças significativas no conteúdo do periódico, notadamente, a diminuição drástica de artigos dedicados à descrição dos programas e a variação dos temas abordados. São apresentadas informações sobre a educação em outros países, por meio da publicação dos programas de uma escola secundária feminina da Prússia, do ensino de Matemática na Alemanha e, em 1915, o professor Isaac Kandel dedicou-se a uma série de cursos e palestras sobre educação comparada, na área de Sociologia Educacional, que contou com a participação de autores estrangeiros.

A seção denominada Notas departamentais, antes esporádica, ganhou espaço e nela são notificadas as palestras e os seminários realizados, relatados os trabalhos desenvolvidos pelos diferentes departamentos, a chegada de alunos bolsistas estrangeiros, as defesas de teses, a nomeação de professores para outras escolas ou cargos e, até mesmo, a comemoração do aniversário do diretor com descrição do presente que the foi oferecido. Além das efemérides, as Notas anunciam a trajetória profissional dos egressos e a criação de um clube para melhoria da prática educacional, iniciativa de ex-alunos do curso Princípios Educacionais de John Dewey, ministrado por William Kilpatrick, bem como a oferta de 250 cursos de verão no ano de 1915, sendo 33 deles inteiramente novos (v. 16, n. 4).

A valorização da pesquisa empírica se fortalece e Frederick Bonser coordena um conjunto de relatos de estudos desenvolvidos na Speyer School, com a avaliação de seus resultados $(1911$, v. 12, n. 1). Entre os autores, sobressai a figura de Edward Thorndike, 
que, além de responsável pelo programa de Psicologia da Educação na formação de professores, publica resultados de estudos, procedimentos e escalas para avaliação do desempenho de alunos em diferentes conteúdos. A tendência de avaliar os resultados da instrução é criticada e defendida nos números subsequentes do periódico, sem desmerecer, no entanto, o avanço que tais estudos possibilitariam.

A partir de 1915 os artigos são dedicados, prioritariamente, à discussão de valores educacionais e, por meio desse redirecionamento, pode-se perceber que o tempo dos modelos a serem imitados dava lugar às reflexões sobre o futuro da educação e da sociedade. O impacto da Primeira Guerra Mundial se torna tema incontornável e a abordagem das questões a ela relacionadas vão, pouco a pouco, entrelaçando aspectos institucionais, políticos e pedagógicos que culminam com a defesa da necessidade de renovação dos métodos de ensino e, consequentemente da formação de professores para acompanhar as mudanças da sociedade.

Não por acaso, o Teachers College assumia nova posição no arranjo universitário. Em 1915 (v. 16, n. 4) foi firmado novo acordo com a universidade que, entre outras decorrências, criava um departamento de Pesquisa Educacional na Faculdade de Filosofia, indicativo da importância adquirida pela área. Nos números subsequentes são apresentadas as exigências para obtenção do doutorado junto à Faculdade e anuncia-se a constituição do corpo docente: James Russell, Paul Monroe, Edward Thordinke, George Strayer, Julius Sachs, John Dewey e Frank McMurry (1916, v. 17, n. 4). A educação deixava de ser um campo voltado para a profissionalização e tornava-se, institucionalmente, lugar de produção de conhecimento científico.

Entre 1915 e 1920, as Notas departamentais atestam o envolvimento da instituição no esforço de guerra: arrecadação financeira para a compra de uma ambulância motorizada a ser usada na França; organização de palestras e cursos sobre as implicações sociais, educacionais e de natureza prática provocadas pelo conflito; oferecimento de minicursos sobre atendimento de emergência; cooperação para a realização de exame psicológico de recrutas; comissionamento de docentes para tarefas administrativas e cessão de prédios escolares para uso do exército americano. As notas permitem inferir que o Teachers College ampliava o seu valor simbólico, estendendo-o para além dos aspectos estritamente ligados à escolarização.

Em 1916 o periódico reproduz um conjunto de conferências dedicadas à análise da relação entre Estado e educação. A primeira é de James Russel (1916, v. 17, n. 2), diretor do Teachers College, que convida experts em diferentes áreas do conhecimento para discutir os princípios básicos nos quais deve se fundamentar o sistema educacional, tendo em vista o fortalecimento da cidadania nas sociedades democráticas. Entre os conferencistas estão John Dewey ${ }^{7}$, Edward Thorndike, Charles Beard, professor de Política, Isaac Kandel, professor de Administração da Educação e Samuel MacCune

\footnotetext{
${ }^{7}$ Embora sem registro nas páginas do periódico, deve-se mencionar que uma das obras de maior repercussão de John Dewey - Democracia e educação - foi publicada nesse mesmo ano e nela, a relação entre escola e sociedade é tematizada tendo por objetivo o investimento na democracia como modo de vida (Cunha, 2001). 
Lindsay, professor de Legislação Social da Universidade. Por meio da análise comparativa entre legislação, organização do estado e resultados sociais avaliam, em linhas gerais, que a educação submissa ao Estado não incrementa a vida democrática.

A discussão sobre educação e democracia não ficou restrita ao âmbito doutrinário, pois é possível detectar o adensamento de artigos sobre práticas que referendariam a formação em novos moldes. John Woodhull (1916), professor de Ciências Físicas do Teachers College, publicou artigo denominado Projects in science no qual indaga por que a escola usa métodos diferentes daqueles prevalecentes na vida cotidiana e que já provaram sua eficiência em diferentes áreas (Woodhull, 1916). No mesmo número Thomas Briggs (1916), professor associado do Teachers College, aponta a relação entre procedimentos de ensino e novos materiais didáticos; o tema prossegue com a colaboração de George D. Von Hofe Jr. (1916), que questiona por que os professores se dedicam ao desenvolvimento de projetos na preparação das aulas para apresentá-los aos alunos como lição pronta e acabada.

Se a defesa dos valores democráticos no plano político era consensual, a discussão sobre os caminhos mais efetivos para atingi-los foi se tornando mais acirrada, conferindo relevância às questões metodológicas.

Nas Notas departamentais publicadas em 1917 (v. 18, n. 1) foi anunciado que o Teachers College tinha obtido fundos financeiros de um comitê fundado por John Rockefeller, destinados a estabelecer e criar uma escola de ciência experimental, que se tornaria, posteriormente, a Lincoln School. Nela deveriam ser testados métodos para obter melhores resultados no ensino de Inglês, Francês e Alemão e nenhum conteúdo deveria ser incluído no currículo por seu valor disciplinar, mas sim por sua adaptação às necessidades da vida cotidiana. Salientava-se que tal projeto, envolvendo entre 150 e 200 alunos, seria conduzido com o mesmo frescor de ponto de vista e com a mesma acuidade científica presentes na pesquisa médica ou num laboratório de agricultura experimental.

No número seguinte, Maurice A. Bigelow (1917), professor do Teachers College, responde à Abraham Flexner ${ }^{8}$, gestor do fundo Rockefeller, argumentando a favor da manutenção dos conhecimentos não diretamente relacionados às questões práticas, afirmando que a ciência aplicada deveria decorrer de uma sólida fundamentação teórica, tarefa precípua da escola.

Em 1918, William Kilpatrick (1918) publicou um pequeno artigo com o qual pretendia esclarecer alguns termos usados nas propostas educacionais que emergiam; trata-se de The project method. Assumindo as proposições gerais de John Dewey, o autor investiu esforços na esfera da implementação dessa concepção, reconhecendo as dificuldades que se apresentam. Para ele, no problema do método de ensino estão relacionados importantes aspectos do processo educativo que envolvem procedimentos, aplicação das leis da aprendizagem e elementos éticos da conduta. Método, em geral, diz respeito ao caráter praticável de uma teoria educacional e contribui para concretizar os objetivos estabelecidos. Nesta perspectiva, a participação dos alunos num projeto agregaria comprometimento, valor psicológico imprescindível, a uma situação social e possibilitaria,

\footnotetext{
${ }^{8}$ Em suas proposições, Abraham Flexner, membro do Conselho de Educação da cidade de Nova York, criticava de modo contundente o currículo escolar pelo fato dos conteúdos estarem desvinculados da utilidade e não desenvolverem a capacidade de pensar criticamente. Essas proposições foram o ponto de partida para a criação da Lincoln School of Teachers College em 1917 (Towsend, 1954). 
além da realização prática, a avaliação comparativa. Sua significação poderia estender-se para o futuro justamente porque o engajamento é a atitude desejada nas sociedades democráticas. Repetindo John Dewey, Kilpatrick afirmava que a riqueza da vida provinha da sucessão de atividades que congregam efeito educativo e que, se as demandas da sociedade coincidirem com os interesses da criança, estarão criadas as condições para que o trabalho em grupo determine a conduta ${ }^{9}$.

A divergência é apresentada no número subsequente do periódico. $O$ artigo de William C. Bagley (1918), professor de Educação do Teachers College, clamou pelo fortalecimento da disciplina nas escolas como fator de fortalecimento da democracia. Para o autor, conteúdo e método de instrução deviam ser enfatizados contra a tendência de valorizar o imediato e o local em detrimento do que é permanente e universal.

$\mathrm{Na}$ defesa da renovação dos métodos, a pesquisa e a experimentação funcionaram como âncoras. No ano de 1919 foi publicado o relatório de estudos desenvolvidos na educação elementar da Escola Horace Mann, com a participação de professoras e alunos das séries iniciais, liderados por William Kilpatrick. O objetivo de tal empreendimento era pôr em prática processos de aprendizagem diferenciados para formular de modo mais preciso os problemas que envolvem a teoria e a prática pedagógica. Seguindo os padrões de cientificidade corrente, as classes foram divididas em grupos experimentais e grupos controle e os mesmos testes foram aplicados em todos os grupos a fim de comparar os resultados obtidos. O texto de Kilpatrick (1919), reprodução da palestra que fez aos pais dos alunos envolvidos na pesquisa, afirma que o que as crianças aprendem pode ser dividido em quatro grupos: conhecimentos comuns sobre o mundo destinados a introduzilos na vida social mais ampla; ideais sociais e habilidades para a vida em grupo; atitudes pessoais relacionadas à melhoria individual e coletiva e, finalmente, as habilidades propriamente escolares, ler, escrever e as operações matemáticas.

Segundo o autor, o último grupo, sempre valorizado pela escola não é, na perspectiva adotada, considerado mais importante que os outros. Para evitar certos resultados indesejáveis da antiga forma de ensinar, o propósito fundamental era demonstrar os méritos de aprender fazendo e, para tanto, foram tomados como base de trabalhos singular: trabalho os impulsos naturais das crianças - para a atividade, para a curiosidade e para estar com outras crianças -; a conexão da aprendizagem com os interesses e com atividades bem sucedidas, que lhe conferem durabilidade e o trabalho docente habilidoso, que auxilia no desenvolvimento de interesses e guia as atividades para fins pertinentes.

Embora seja possível afirmar que a tendência à mudança nos métodos de ensino fortalecia-se nas páginas do periódico ano após ano, havia também resistências. Stuart $A$. Courtis (1920), diretor de Pesquisa Educacional das Escolas Públicas de Detroit, afirmava que há aceitação entre os professores quanto à necessidade de mudar o currículo e introduzir mais liberdade e espírito democrático na instituição escolar, mas existe também o temor que as novas formas de trabalho não desenvolvam adequadamente as habilidades fundamentais de leitura, escrita, composição e aritmética, atribuições

\footnotetext{
${ }^{9}$ George D. Hofe publicou em 1966 um artigo no qual atribui ao professor Woodhull a primazia na utilização do método de projetos no processo de aprendizagem, com o qual pretende corrigir informações presentes numa biografia de Kilpatrick (Hofe, 1966). 
essenciais da escola elementar. Dispostos a introduzir mudanças qualitativas em suas práticas, os professores ouvem falar do método de projetos, assistem demonstrações de aulas, leem artigos em periódicos, mas, em dúvida sobre seus resultados, continuam a trabalhar com procedimentos mais seguros porque não dispõem das mesmas condições que existem nas escolas experimentais.

Como resposta ou estratégia para minimizar questionamentos, no mesmo número da revista foi publicado, por sugestão de Kilpatrick, um levantamento da bibliografia já produzida sobre o método de projetos (Herring, 1920). A listagem de obras atribui lastro ao método, pois indica que a primeira obra sobre o tema é de 1895, embora a produção tenha se adensado entre 1915 e 1920. O artigo também vincula, inequivocamente, as proposições de John Dewey ao método de projetos, pois é o autor com maior número de referências no levantamento, inclusive da mais antiga, e suas obras mais teóricas como Democracia e educação e Como pensamos estão aí arroladas, além de outros trabalhos mais específicos como $A$ criança e o currículo e Interesse e disciplina. A bibliografia coligida procura superar as dificuldades para a adoção do método apresentando um número significativo de obras que exemplificam seu desenvolvimento com diferentes conteúdos e em diferentes níveis de instrução.

Outro exemplo vem de um relatório de Gertrude Bigelow (1920), professora da Escola Horace Mann, descrevendo como um programa escolar convencional poderia ser transformado numa organização curricular por projetos, isto é, alterando o método e mantendo os conteúdos. A autora afirma que o contraste mais visível entre o curso organizado por matérias e aquele organizado por projetos é que, neste último, o programa serve como orientação e não como imposição para o professor e para os alunos desenvolverem atividades de seu interesse. Nessa organização o tempo destinado às atividades livres da criança é, para o professor, tempo de observação e estudo das reações e necessidades surgidas, que determinam, em larga medida, o programa diário e contribuem para definir atividades que atendam às exigências dos conteúdos.

Em 1921 o periódico publicou os resultados do simpósio denominado Perigos e dificuldades do método de projetos e como enfrentá-los. Kilpatrick sintetiza, na abertura e na conclusão do evento, as questões ali privilegiadas. No texto de abertura (Kilpatrick, 1921a), reitera algumas características do método de projetos, entendendo-o como uma unidade de experiência intencional que determina o objetivo de uma ação, guia seu processo e fornece motivação. Exemplifica mais detalhadamente a tipificação dos projetos apresentada no texto anterior e reafirma que todos os tipos têm em comum a ação intencional e devem agregar a cooperação coletiva por meio da qual se articulam com os valores sociais. Nessa introdução o autor antecipa explicações e aplaca temores, assegurando que, embora o projeto possa ser sugerido tanto pelos professores como pelos alunos, cabe ao professor o controle da situação para que as intenções mais desejáveis possam ser desenvolvidas.

Como costuma acontecer, a projeção mais realista do desfecho do embate está apresentada na argumentação do antagonista. William C. Bagley (1921) questiona as premissas do método de projetos e reconhece que sua adoção pode mudar totalmente a vida escolar e os padrões de pensar e agir das futuras gerações. Entende, argutamente, que não se trata apenas de um método de ensino, mas de um novo ponto de vista educacional e reclama mais avaliações experimentais. Questiona se é seguro afirmar que 
o conhecimento adquirido por meio de experiências específicas pode ser transferido para outros conteúdos e situações e considera que priorizar a liberdade de intenção da criança ao invés da comunidade de cultura implica excessiva valorização dos conteúdos instrumentais em detrimento da herança cultural da espécie ${ }^{10}$, bem como a destituição da centralidade do professor no processo de ensino. Conclui afirmando que o controle do adulto sobre a criança é próprio da condição infantil e, usando a terminologia de Kilpatrick, considera essa uma atitude virtuosa.

Todos os outros artigos do simpósio apresentam posições favoráveis ao método de projetos. Bonser (1921) centra-se na superação das dificuldades, entre elas as interpretações errôneas mais frequentemente apontadas: limitar o método de projetos a atividades construtivas; considerar com o mesmo valor todos os interesses das crianças, prescindindo da seleção do professor; adotar o nome sem adotar o espírito dos projetos; selecionar projetos de realização individual e não coletiva; negligenciar os exercícios, os sumários e a sistematização do conhecimento. Para o autor, o aprofundamento da concepção metodológica consiste em relacionar método, filosofia educacional, psicologia educacional, estudo da vida e do conteúdo escolar, o que requer investimentos na formação do professor.

Hosic (1921) destaca entre as vantagens do método de projetos a criação de oportunidades para o exercício dos princípios democráticos - objetivos comuns, espírito de cooperação, divisão do trabalho -, citando as proposições de John Dewey. Hatch (1921), professor de História da Escola Horace Mann, pôs em prática o método, juntamente com os estudantes do curso de formação de professores e avalia que entre as vantagens estão à disponibilização de mais fontes e mais referências para estudo próprias da atitude científica; o aumento da autonomia e da confiança para organizar as informações obtidas; o treino do pensamento lógico; a partilha de ideias, tolerância e uso do diálogo como procedimento. Entre as desvantagens são apontados o excesso de tempo dedicado a discussões pouco importantes; a possibilidade de alguns alunos não terem bom desempenho no grupo; o encorajamento da expressão não fundamentada e a quebra de continuidade do trabalho mental. Pesados os prós e os contras da enquete por ele realizada, o autor conclui que a dificuldade estaria na calibragem das atividades e não no uso do método propriamente dito e que, embora o professor continue sendo um guia na sala de aula, a responsabilidade na condução dos trabalhos é compartilhada com os alunos.

Ao final do simpósio Kilpatrick (1921b) fez um balanço dos diferentes pontos de vista apresentados e, citando Dewey, reafirmou a necessidade de compatibilizar os dois fatores fundamentais do processo educativo - a criança e a experiência da espécie - e de enfrentar as dificuldades que se apresentam no âmbito prático: como fazer. Considerou que a atividade comprometida e intencional se desenvolve melhor quando há identificação entre a educação e a vida e, em resposta às críticas e questionamentos apresentados

\footnotetext{
${ }^{10}$ I should answer this question by suggesting that knowledge or race experience furnishes an equipment for life over and above the tools or instruments that it supplies, - something that is perhaps even more fundamental than tools or instruments. It furnishes foundations, backgrounds, perspectives, points of view, attitudes, tastes, and a host of other things that determine conduct in a very real fashion, and yet through devious channels that are likely to defy analysis and to escape the scrutiny of one who is looking only for direct and visible applications (Bagley, 1921). 
pelo professor Bagley, notadamente aqueles referentes à atividade docente ${ }^{11}$, assegura que cabe ao professor julgar a pertinência dos interesses manifestados pelos alunos, preparar-se para encontrar os melhores caminhos e procedimentos e criar oportunidades para a sistematização do conhecimento adquirido. Conclui afirmando que perspectivas inovadoras demandam novos procedimentos e que o objetivo de unir a escola à vida requer investimento nos métodos e na sistematização deles.

O simpósio, aparentemente, encerrou as discussões já que o tema arrefeceu nas páginas do periódico indicando que a defesa do ensino organizado em torno de projetos foi vitoriosa. As poucas considerações contrárias foram respeitosamente reconfiguradas como problemas a serem superados e foram computados os ganhos em termos de sociabilidade, capacidade de diálogo e trabalho coletivo, requisitos para a participação ativa na sociedade democrática.

Numa chave diferente daquela da primeira década, as questões sobre como ensinar e o que ensinar permaneceram como elementos centrais do debate e, pode-se dizer, encobriram o elo que as une, isto é, a formação de professores necessária aos propósitos renovadores. No entanto, um novo modelo de formação estava sendo posto em circulação: a pesquisa e a experimentação, próprias das instituições universitárias, substituíram as prescrições detalhadas para a formação de professores, incompatíveis com a organização curricular mais flexível dos projetos de ensino. Nesse processo o Teachers College, da Universidade Colúmbia, e seu periódico Teachers College Record, cujo dístico é the voice of scholarship in education, constituíram-se em polos irradiadores da educação progressiva, denominação que expressava, simultaneamente, reformas educacionais, filosofia da educação e métodos de ensino.

\section{Um tema ainda em aberto}

Um esclarecedor artigo de balanço do movimento da educação progressiva foi publicado pelo historiador Lawrence Cremin (1959), no Teachers College Record, no qual descreve as diferentes vertentes que foram abrigadas sob a mesma expressão e sugere algumas razões para o seu declínio. Considera como marcos a criação, em 1919, e o encerramento, em 1955, da Progressive Education Association, e de seu periódico, em 1957, como o fim de uma era marcada pela tentativa de aplicar ideais de governo mais generosos à fragmentada sociedade norte-americana urbana e industrial no início do século 20 , que, no entanto, não resistiram ao ideário conservador que se seguiu à Segunda Guerra.

\footnotetext{
${ }^{11}$ Are we not then reduced to admitting that on this theory the child is after all the arbiter and judge of what he shall undertake? To which I should answer "No." I, at any rate, have no intention of giving up adult control. In my school the teacher shall remain, under the proper authorities, the final arbiter of what shall be done in the school room. [...] The right to decide is the teacher's. The teacher for educative purposes will wish the children to be engaged as far as may be possible in purposeful activities. This on the side of method and good learning conditions. But the teacher will also wish and demand, and so far as I can effect it, successfully demand, that the activities be not only purposeful, that is, heartily accepted as one's own, but also fruitful, worthy, desirable. This from the point of view of subject-matter and race experience, the direction of growing. The teacher will hope for and seek both purpose, or acceptance, and worthiness in one and the same activity. In this world we seldom get all we seek. Whether the proposed activity lacks in worthiness, the teacher must decide. [...] From first to last the decision is ultimately in the teacher's hands unless he, on account of known conditions, chooses to leave the matter tentatively and within limits in the child's hands (Kilpatrick, 1921b).
} 
Estudos mais recentes têm procurado alternativas para incorporar autores e concepções que foram negligenciados durante o longo tempo de hegemonia conquistada pela concepção progressiva, provocando assim, um exame crítico do legado dessa tendência educacional. Labaree (2005) afirma que o progressivismo teve impacto na retórica educacional norte-americana e reduzidas aplicações práticas e questiona, junto com a concepção, a eficácia da formação de professores no nível universitário polarizada entre demandas profissionais e investimento na pesquisa (Labaree, 2004). Kliebard (2004, 2006), por sua vez, entende que houve desvirtuamento da filosofia de Dewey e que seu potencial ainda pode guiar as reformas necessárias à educação atual. Na mesma perspectiva, posicionam-se autores que retomam a relação entre educação e política ou entre educação e democracia, que permanecem desafiando reformadores educacionais (Hansen, 2006 e Benson; Harkavy e Puckett, 2007).

No âmbito da revisão historiográfica propriamente dita, o trabalho de Ogren (2005) contrapõe-se aos estudos que reduzem a história da formação de professores à história das instituições universitárias de elite para defender a contribuição das escolas normais na democratização da educação. Null (2003) e Null e Ravitch (2006) investem na compilação e análise da obra de autores que, segundo eles, perderam as grandes batalhas pedagógicas do século 20 e cujas proposições foram silenciadas. Entre esses autores estão William Bagley, William Harris e Charles McMurry, interlocutores de presença importante nas páginas do Teachers College Record.

A discussão que se apresenta nesses estudos reafirma o entrelaçamento, na formação de professores, dos aspectos políticos, teóricos e práticos cuja complexidade permanece até os dias de hoje.

\section{Referências}

BAGLEY, William Chandler. Dangers and difficulties of the Project method and how to overcome them: II. Projects and purposes in teaching and in learning. Teachers College Record, v. 22, n. 4, 1921, p. 288-296.

BAGLEY, William Chandler. The place of duty and discipline in a democratic scheme of education. Teachers College Record, v. 19, n. 5, 1918, p. 419-430.

BENSON, Lee; HARKAVY, Ira; PUCKETT, John. Dewey's dream: universities and democracies in an age of education reform civil society, public schools, and democratic citizenship. Philadelphia: Temple University Press, 2007.

BIGELOW, Gertrude I. Horace Mann studies in primary education: the course of study and the program in the project method. Teachers College Record, v. 21, n. 4, 1920, p. 327336.

BIGELOW, Maurice. Science in the modern school. Teachers College Record, v. 18, n. 2, 1917, p. 134-140.

BONSER, Frederick G. Dangers and difficulties of the project method and how to overcome them: III. Dangers and difficulties of the project method. Teachers College Record, v. 22, n. 4, 1921, p. 297-305.

BONSER, Frederick G. Studies in elementary school practice. Teachers College Record, v. 12 , n. 1, 1911, p. 1-2. 
BRIGGS, Thomas H. General science in secondary schools. Teachers College Record, v. 17 , n. 1, 1916, p. 19-30.

COURTIS, Stuart A. Teaching through the use of projects or purposeful acts. Teachers College Record, v. 21, n. 2, 1920, p. 139-149.

CREMIN, Lawrence Arthur. What happened to progressive education? Teachers College Record, v. 61, n. 1, 1959, p. 23-29.

CUNHA, Marcus Vinicius da. A utopia democrática. Rio de Janeiro: DP\&A, 2001.

DUTTON, Samuel T; PEARSON, Henry. The curriculum of elementary school. Teachers College Record, v. 5, n. 2, 1904, p. 28-97.

DUTTON, Samuel T. The motives and principles underlying the work of the Horace Mann Elementary School. Teachers College Record, v. 5, n. 2, 1904, p. 1-7.

FRASER, James W. Preparing america's teachers: a history. New York: Teachers College Columbia University, 2007.

HANSEN, David T (ed.). John Dewey and our educational prospect. Albany: State University of New York Press, 2006.

HATCH, R. W. Dangers and difficulties of the project method and how to overcome them: V. student reaction to the project method. Teachers College Record, v. 22, n. 4, 1921, p. 306- 310.

HERRING, John P. Bibliography of the project method. Teachers College Record, v. 21, n. 2, 1920, p. 150-174.

HERVEY, Walter L. Historical sketch of Teachers College from its foundation to 1897. Teachers College Record, v. 1, n. 1, 1900, p. 12-35.

HILL, Patty S; DEWEY, John. Experimental studies in kindergarten: theory and practice. Teachers College Record, v. 15, n. 1, 1914, p. 9-15.

HOFE, George Douglas. The project method: Its origin. Teachers College Record, v. 67, $n$. 5, 1966, p. 371-337.

VON HOFE JR, George D. The development of a project. Teachers College Record, v. 17, n. 3, 1916, p. 240-246.

HOSIC, James Fleming. Dangers and difficulties of the project method and how to overcome them: IV. The project method. Teachers College Record, v. 22, n. 4, 1921, p. 305-306.

KILPATRICK, William Heard. Dangers and difficulties of the project method and how to overcome them: I. Introductory statement: definition of terms. Teachers College Record, v. 22, n. 4, 1921a, p. 283-287.

KILPATRICK, William Heard. Dangers and difficulties of the project method and how to overcome them: VI. A review and a summary. Teachers College Record, v. 22, n. 4, 1921b, p. 310-321.

KILPATRICK, William Heard. The theories underlying the experiment. Teachers College Record, v. 20, n. 2, 1919, p. 97-125.

KILPATRICK, William Heard. The project method. Teachers College Record, v. 19, n. 4, 1918, p. 319-335.

KLIEBARD, Herbert M. The struggle for the American curriculum (1893-1968). New York: Routledge Falmer, 2004. 
KLIEBARD, Herbert M. Dewey's reconstruction of the curriculum: from occupations to disciplined knowledge. In: HANSEN, T. D (ed.). John Dewey and our educational prospect. Albany: State University of New York Press, 2006.

LABAREE, David F. Progressivism, schools and schools of education: an American romance. Paedagogica histórica, v. 41, n. 1-2, 2005, p. 275-288.

LABAREE, David F. The trouble wit Ed Schools. New Haven: Yale University Press, 2004.

MCMURRY, Frank. Curriculum of kindergarten and first five grades of elementary school. Teachers College Record, v. 4, n. 1, 1903, p. 12-50.

MCMURRY, Frank. Method of solution of educational problems. Teachers College Record, v. 5, n. 3, 1904, p. 1-6.

MCMURRY, Frank. Practical work of undergraduate students of Teachers College. Teachers College Record, v. 4, n. 1, 1903, p. 60-79.

NULL, J. Wesley; RAVITCH, Diane. Forgotten heroes of American Education: the great tradition of teaching teachers. Greenwich: Information Age Publishing, 2006.

NULL, J. Wesley. A disciplined progressive educator: the life and career of William Chandler Bagley. New York: Peter Lang, 2003.

OGREN, Christine A. The American state normal school: an instrument of great good. New York, Palgrave MacMillan, 2005.

RICHARDS, Charles. A basis for unification in the primary grades. Teachers College Record, v. 5, n. 2, 1904. p. 12-19.

RUSSELL, James E. The organization and administration of Teachers College. Teachers College Record, v. 1, n. 1, 1900a. p. 41-46.

RUSSELL, James E. The organization and administration of Teachers College. Teachers College Record, v. 1, n. 1, 1900b. p. 46-51.

RUSSELL, James E. The organization and administration of Teachers College. Teachers College Record, v. 1, n. 1, 1900c. p. 39-41.

SIRINELLI, Jean-François. As elites culturais. In: RIOUX, Jean-Pierre; SIRINELLI, JeanFrançois. Para uma história cultural. Lisboa: Estampa, 1998.

Teachers College Record, v. 14, n. 2, 1913.

Teachers College Record, v. 16, n. 4, 1915.

Teachers College Record, v. 17, n. 4, 1916.

Teachers College Record, v. 15, n. 1, 1914.

Teachers College Record, v. 4, n. 1, 1910.

Teachers College Record, v. 14, n. 3, 1913

Teachers College Record, v. 17, n. 2, 1916.

Teachers College Record, v. 6, n. 4, 1905.

TOWSEND, Mary Evelyn. A history of Teachers College Columbia University. Columbia University Press, 1954. In: CREMIN, Lawrence; SHANNON, David Allen; TOWSEND, Mary Evelyn. A history of Teachers College Columbia University. New York: 1954.

WOODHULL, John F. Projects in science. Teachers College Record V. 17, n. 1, 1916, p. 31-39. 
VERA TERESA VALDEMARIN é professora no Departamento de Ciências da Educação da Faculdade de Ciências e Letras de Araraquara e no Programa de PósGraduação em Educação do Instituto de Biociências de Rio Claro, ambos vinculados à Unesp.

Endereço: Faculdade de Ciências e Letras da Unesp - Rodovia Araraquara - Jaú, Km 01 - 14801-900 - Araraquara - SP - Brasil.

Email: vera@fclar.unesp.br.

Recebido em 20 de junho de 2015.

Aceito em 13 de setembro de 2015. 